\title{
Sol-gel synthesis of fluorine-doped silica glasses with low $\mathrm{SiOH}$ concentrations
}

\author{
Ryohei MAEHANA, Shungo KUWATANI, Koichi KAJIHARA ${ }^{\dagger}$ and Kiyoshi KANAMURA \\ Department of Applied Chemistry, Graduate School of Urban Environmental Sciences, Tokyo Metropolitan University, \\ 1-1 Minami-Osawa, Hachioji, Tokyo 192-0397
}

Fluorine-doped monolithic silica glasses with low SiOH concentrations were prepared by a sol-gel method using hydrofluoric acid as a fluorine source. Without employing dehydration of dried gels using halogen-containing gases, or vacuum sintering, the concentration of $\mathrm{SiOH}$ groups was reduced to $\sim 10^{17} \mathrm{~cm}^{-3}$ ( 1 ppmw), which is comparable to that of synthetic silica glasses mildly dehydrated during their vapor-phase synthesis. The fluorine concentration evaluated from the intensity of the Raman band of $\mathrm{SiF}$ groups $\left(\sim 945 \mathrm{~cm}^{-1}\right)$ was in the order of $\sim 10^{20}-10^{21} \mathrm{~cm}^{-3}$.

(-2011 The Ceramic Society of Japan. All rights reserved.

Key-words : Silica glass, Sol-gel method, Low SiOH concentration, Fluorine doping, Dehydration

[Received January 25, 2011 ; Accepted March 4, 2011]

\section{Introduction}

Silica glass is a useful optical material because of its excellent transparency, good radiation hardness, and high chemical stability and mechanical strength. The sol-gel method is a wetchemical process, and is suitable for manufacturing silica glasses at relatively low temperatures $\left(\leq \sim 1300^{\circ} \mathrm{C}\right)$ while incorporating various non-metallic and metallic dopants. However, since water is a key component of the precursor solution, sol-gel derived silica glasses usually contain many $\left(\sim 10^{19}-10^{20} \mathrm{~cm}^{-3}\right) \mathrm{SiOH}$ groups. The $\mathrm{SiOH}$ groups significantly decrease the transmittance in the fiber telecommunication spectral range (wavelength at $\sim 1.5 \mu \mathrm{m}$ ). They also decrease the photoluminescence quantum yield of photoactive centers embedded in silica glasses. The radiation hardness of silica glasses is usually best at moderate $\left(\sim 10^{17}-10^{18} \mathrm{~cm}^{-3}\right) \mathrm{SiOH}$ concentrations. Thus elimination of $\mathrm{SiOH}$ groups is a crucial issue in preparing sol-gel derived silica glasses.

$\mathrm{SiOH}$ groups in silica glasses are commonly removed by doping with halogen atoms, which form $\mathrm{Si}-\mathrm{F}$ or $\mathrm{Si}-\mathrm{Cl}$ bonds in the glasses and replace $\mathrm{SiOH}$ groups. Halogen doping and dehydration are typically performed during sintering of porous silica bodies with flowing gases containing halogen atoms, such as $\mathrm{Cl}_{2},{ }^{1), 2)} \mathrm{SOCl}_{2},{ }^{3)} \mathrm{SF}_{6}$, ${ }^{4)}$ and $\mathrm{SiF}_{4}{ }^{5}{ }^{5}$ However, vapor-phase halogenation during sintering often requires a large excess of flowing halogen-containing gases, and some of these gases are difficult to handle due to corrosiveness, toxicity, and high reactivity. Dehydration by chlorine-containing gases is usually followed by oxidation to remove chlorine species, because chlorine species incorporated in silica glasses are likely to decrease the transparency of the glasses in the vacuum-ultraviolet (VUV) spectral region, ${ }^{6), 7)}$ and form bubbles when heated above $\sim 2000^{\circ} \mathrm{C}^{5 \text { ) }}$

An alternative approach to dehydrating sol-gel derived silica glasses is to incorporate fluorine-based compounds in the precursor solution. HF is a simple fluorine source for such liquid-phase fluorine doping. It also acts as an acid catalyst, and

Corresponding author: K. Kajihara; E-mail: kkaji@tmu.ac.jp its role in hydrolysis and polycondensation has been thoroughly examined. ${ }^{8), 9)}$ It is most likely that the surface of HF-catalyzed gels is modified by hydrophobic $\mathrm{SiF}$ groups, which replace $\mathrm{SiOH}$ groups and suppress the surface absorption of $\mathrm{H}_{2} \mathrm{O} .{ }^{10), 11)}$ Thus, in silica glasses derived from HF-catalyzed silica gels, the concentration of $\mathrm{SiOH}$ groups is effectively lowered. ${ }^{12)}$ In addition, the average pore size of gels catalyzed by HF is generally larger than that of gels catalyzed by other conventional acids, ${ }^{13)-15)}$ making it possible to suppress fracture during drying. These properties of HF are useful in forming monolithic silica glasses with low $\mathrm{SiOH}$ concentrations. Other fluorine sources employed to prepare fluorine-doped silica glasses include alkoxides containing $\mathrm{Si}-\mathrm{F}$ bonds, such as fluorotrimethoxysilane ${ }^{16)}$ and fluorotriethoxysilane. ${ }^{17), 18)}$ Inorganic compounds containing fluorine, such as alkali fluorides, ${ }^{8), 19)} \mathrm{NH}_{4} \mathrm{~F},{ }^{5} \mathrm{H}_{2} \mathrm{SiF}_{6},{ }^{20)}$ and $\mathrm{SiF}_{4},{ }^{20)}$ may also be used as fluorine sources and dehydrating agents. However, probably because the elimination of $\mathrm{SiOH}$ groups by the liquidphase fluorine doping alone was often insufficient, postdehydration during sintering using halogen-containing gases ${ }^{7)}$ or vacuum sintering ${ }^{21), 22)}$ has been commonly employed. It is also unclear how liquid-phase fluorine doping can reduce the concentration of $\mathrm{SiOH}$ groups in sol-gel derived silica glasses, although samples whose $\mathrm{SiOH}$ concentrations are as low as 4 ppmw have been prepared by oxygen sintering of fluorinemodified gels. ${ }^{18)}$

In the present study, we report sol-gel preparation of fluorinedoped, chlorine-free silica glasses with low $\mathrm{SiOH}$ concentrations, from solutions catalyzed by $\mathrm{HF}$. The $\mathrm{SiOH}$ concentration is found to be decreased to as low as $\sim 10^{17} \mathrm{~cm}^{-3}$ ( $\sim 1 \mathrm{ppmw}$ ) by densification under a helium atmosphere, without employing post-dehydration during sintering and vacuum sintering.

\section{Experimental procedure}

Tetraethoxysilane (TEOS, Shin-Etsu Chemical), ethanol, water, and hydrofluoric acid $(\sim 48 \mathrm{wt} \%)$ were mixed in the molar ratio TEOS:EtOH: $\mathrm{H}_{2} \mathrm{O}: \mathrm{HF}=1: 4: x_{1}: 0.1$, and the solution was stirred for $t_{\mathrm{PH}}$ min at $20^{\circ} \mathrm{C}$ to partially hydrolyze TEOS. The solution was then mixed with additional water, and stirred for $2 \mathrm{~min}$ to form a clear solution. Stirring was then stopped, and the 
solution was allowed to gel at $20^{\circ} \mathrm{C}$ in a sealed container. The overall molar ratio of the solution was fixed at TEOS:EtOH: $\mathrm{H}_{2} \mathrm{O}: \mathrm{HF}=1: 4: 5\left(=x_{1}+x_{2}\right): 0.1$, where $x_{2}$ denotes the fraction of water added in the second mixing. The resultant wet gel was aged for $t_{\mathrm{A}}$ days at $80^{\circ} \mathrm{C}$ by placing the sealed container in an oven. Then the solvent phase was removed after opening the container and the gel was dried gently using a cover with a hole (diameter $1.5 \mathrm{~mm}$ ) in the same oven. The fluorine content of the solvent phase was measured spectrophotometrically using a lanthanum(III)-alizarin complexone reagent (Alfusone, Dojindo Laboratories). The dried gel was sintered in a tube furnace heated at $200^{\circ} \mathrm{Ch}^{-1}$ to $1200^{\circ} \mathrm{C}$, and maintained for $1 \mathrm{~h}$ at that temperature. The oven atmosphere was switched from air to helium at $600^{\circ} \mathrm{C}$. Optical absorption spectra of the resultant silica glasses were measured with conventional (U-4100, Hitachi) and VUV (VU-201, Bunkou-keiki/JASCO) spectrometers. Raman spectra were recorded with a dispersive micro-Raman spectrometer (NRS-1000, JASCO), using a $20 \times$ objective lens (SLMPlan, Olympus) and excitation at $532 \mathrm{~nm}$. Several dried gels were calcined for $1 \mathrm{~h}$ at $300^{\circ} \mathrm{C}$ in air and the resulting mesoporous structure was characterized by measuring nitrogen adsorptiondesorption isotherms (BELSORP-mini, BEL Japan).

\section{Results}

After the second mixing, the solution became a transparent wet gel in $\sim 70 \mathrm{~min}$ at $20^{\circ} \mathrm{C}$, and was converted to semi-transparent dried gel after aging and drying at $80^{\circ} \mathrm{C}$. The fraction of fluorine dissolved in the solvent phase before drying, determined by the lanthanum(III)-alizarin complexone method, was $\sim 1 \%$ of the fluorine added as HF in the precursor solution, suggesting that dried gels contained almost all of the fluorine added initially. Sintering of the dried gels in a helium atmosphere yielded crackfree monolithic silica glasses. Figure 1 shows photographs of a typical dried gel and a silica glass prepared by this procedure with $x_{1}=1, t_{\mathrm{PH}}=15 \mathrm{~min}$, and $t_{\mathrm{A}}=2$ days. Gels prepared from $5.2 \mathrm{~g}$ of TEOS were routinely dried without fracture within $\sim 2$ days. Figure 2 shows a nitrogen absorption-desorption isotherm of a dried gel prepared under the same conditions as the gel shown in Fig. 1(a). The pore size distribution curve shown in the inset was calculated from the adsorption branch of the isotherm using the Barrett-Joyner-Halenda method. ${ }^{23)}$ The observed average pore diameter was $\sim 25 \mathrm{~nm}$, which was larger than that of gels prepared using conventional acid catalysts $(\sim 1-$ $10 \mathrm{~nm}){ }^{8), 15)}$ The surface area evaluated from the BrunauerEmmett-Teller method ${ }^{24)}$ was $\sim 300 \mathrm{~m}^{2} \mathrm{~g}^{-1}$. Figure 3 shows

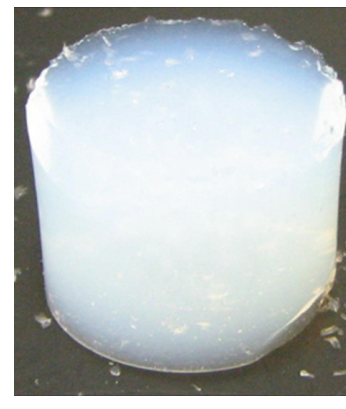

(a)

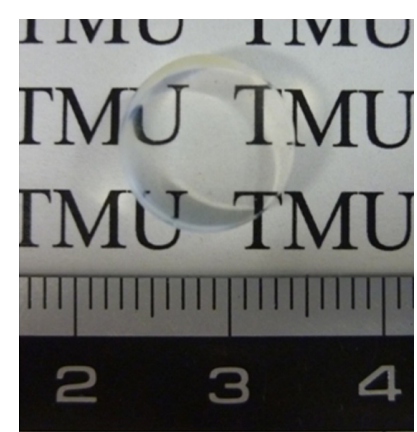

(b)
Fig. 1. (Color online) Photograph of (a) a dried gel and (b) a silica glass, prepared from $5.2 \mathrm{~g}(25 \mathrm{mmol})$ of TEOS at $x_{1}=1, t_{\mathrm{PH}}=15 \mathrm{~min}$, and $t_{\mathrm{A}}=2$ days, followed by drying for $\sim 2$ days.

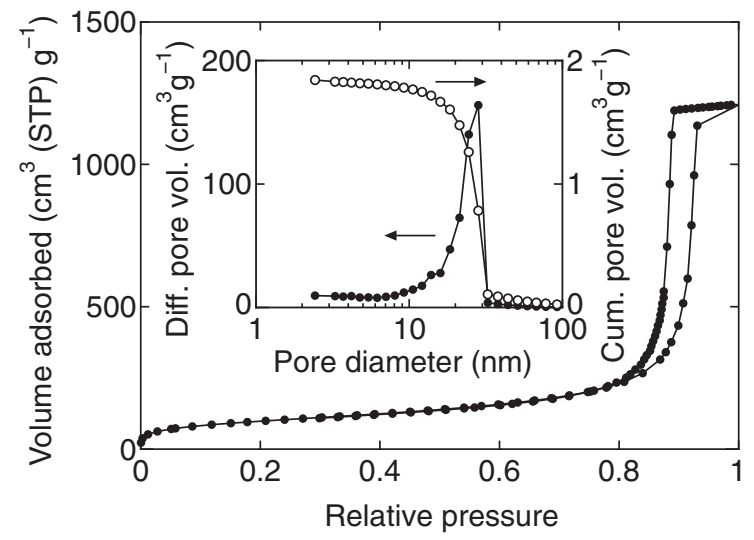

Fig. 2. Nitrogen adsorption-desorption isotherm, pore size distribution curve, and cumulative pore volume of a gel prepared at $x_{1}=1$, $t_{\mathrm{PH}}=15 \mathrm{~min}$, and $t_{\mathrm{A}}=2$ days. Prior to the measurement the dried gel was calcined for $1 \mathrm{~h}$ at $300^{\circ} \mathrm{C}$.

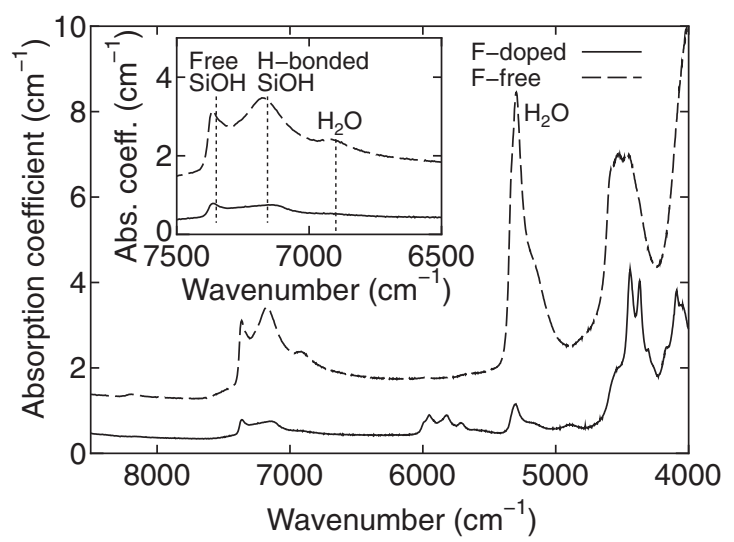

Fig. 3. Infrared absorption spectra of a dried gel prepared prepared at $x_{1}=1, t_{\mathrm{PH}}=15 \mathrm{~min}$, and $t_{\mathrm{A}}=2$ days, and a fluorine-free dried silica gel prepared following the procedure described in Ref. 25) at $x_{1}=2.1$, $x_{1}+x_{2}=10$, and $20^{\circ} \mathrm{C}$. The first overtone bands of the $\mathrm{O}-\mathrm{H}$ stretching modes of free and hydrogen-bonded $\mathrm{SiOH}$ groups as well as $\mathrm{H}_{2} \mathrm{O}$ are magnified in the inset. The upward shift of the spectrum of the fluorinefree sample is due to its larger light scattering.

infrared absorption spectrum of a fluorine-doped gel prepared under the same conditions as that shown in Fig. 1(a). Absorption spectrum of a fluorine-free gel prepared by the procedure reported in Ref. 25) is also presented. The intensity of the absorption bands of SiOH groups at $\sim 7000-7500 \mathrm{~cm}^{-126}$ ) and $\mathrm{H}_{2} \mathrm{O}$ at $\sim 5200-5300$ and $\sim 6900 \mathrm{~cm}^{-111), 27)}$ were smaller in the fluorine-doped gel than in the fluorine-free gel, consistent with the infrared data reported for fluorine-doped gels prepared from solutions containing HF. ${ }^{11)}$

Figure 4 shows an infrared absorption spectrum of the silica glass shown in Fig. 1(b). The intensity of the absorption band at $\sim 3680 \mathrm{~cm}^{-1}$, due to the $\mathrm{O}-\mathrm{H}$ stretching mode of $\mathrm{SiOH}$ groups, was very small. The concentration of $\mathrm{SiOH}$ groups $\left(C_{\mathrm{SiOH}}\right)$ evaluated from the observed peak intensity and the peak absorption cross-section reported in the literature $\left(2.9 \times 10^{-19}\right.$ $\mathrm{cm}^{228)}$ ) was as low as $\sim 1.5 \times 10^{17} \mathrm{~cm}^{-3}(\sim 1.9 \mathrm{ppmw})$, although no special dehydration treatment was performed during sintering. The observed $C_{\mathrm{SiOH}}$ in this sol-gel derived sample is comparable to that of synthetic dry silica glasses prepared by vapor phase methods under mild dehydration conditions $\left(\sim 0.1-1\right.$ ppmw). ${ }^{29), 30)}$ The inset of Fig. 4 shows the Raman spectrum of the fluorine- 


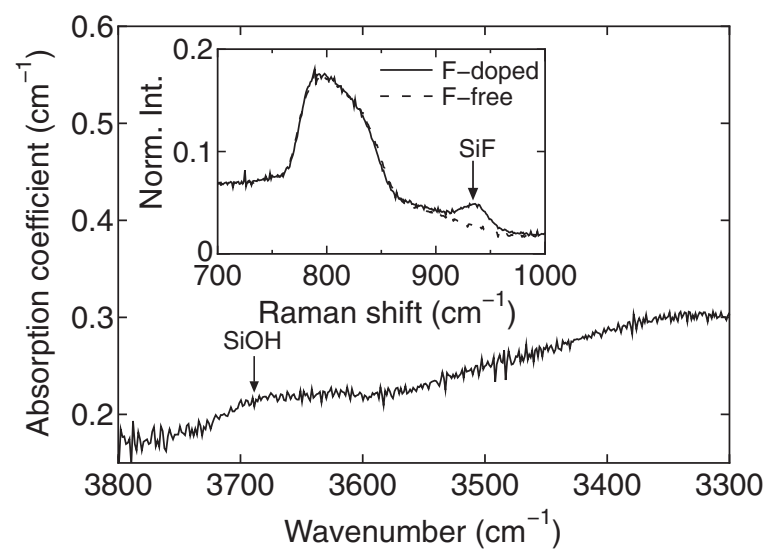

Fig. 4. Infrared absorption spectrum of the fluorine-doped silica glass shown in Fig. 1(a). The inset shows Raman spectra of this sample and of a fluorine-free glass prepared following the procedure described in Ref. 30).

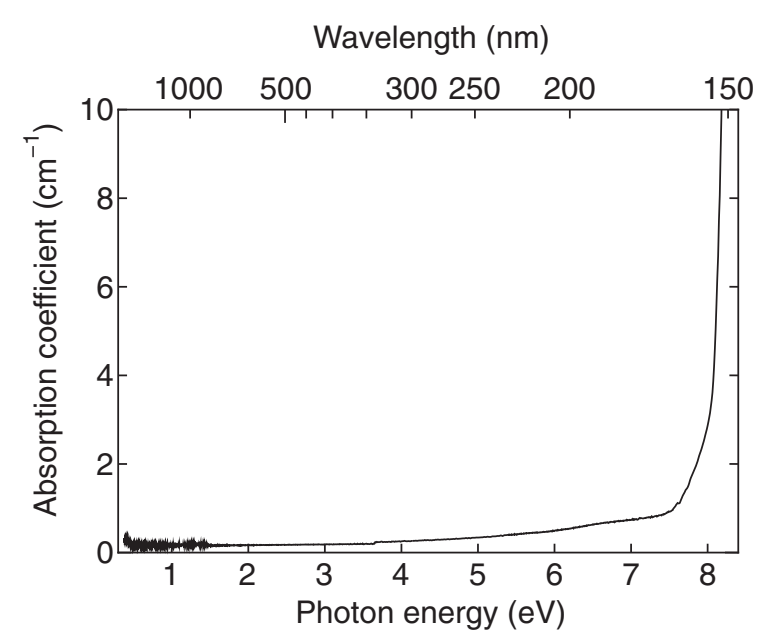

Fig. 5. Absorption spectrum of the fluorine-doped silica glass shown in Fig. 1(a).

doped sample; the spectrum of a fluorine-free sol-gel derived silica glass ${ }^{31)}$ is also shown for comparison. In this fluorinedoped sample the Raman band at $\sim 945 \mathrm{~cm}^{-1}$ attributed to $\mathrm{SiF}$ groups $^{32), 33)}$ is apparent. The concentration of $\mathrm{SiF}$ groups $\left(C_{\mathrm{SiF}}\right)$ evaluated from normalized peak intensities at $\sim 945 \mathrm{~cm}^{-1}$ of the sample and a concentration standard with known $C_{\mathrm{SiF}}$ was $\sim 8 \times 10^{20} \mathrm{~cm}^{-3}\left(\sim 1 \times 10^{4} \mathrm{ppmw}\right)$. The visible-ultraviolet optical absorption spectrum of the same sample is shown in Fig. 5. The resultant sample showed good transparency from nearinfrared to VUV spectral region. Figure 6 shows the depth distribution of $C_{\mathrm{SiF}}$ of a sample prepared under the same conditions as that shown in Fig. 1(b). No systematic gradient of $C_{\mathrm{SiF}}$ across the cross-section of the sample was found.

The effect of preparation conditions on $C_{\mathrm{SiOH}}$ and $C_{\mathrm{SiF}}$ was examined by varying $x_{1}, t_{\mathrm{PH}}$, and $t_{\mathrm{A}}$, and the results are summarized in Fig. 7. The notation $x_{1}=5$ and $t_{\mathrm{PH}}=0 \mathrm{~min}$ refers to the procedure in which all of $\mathrm{H}_{2} \mathrm{O}$ was added in the first mixing (no second mixing). $C_{\mathrm{SiOH}}$ and $C_{\mathrm{SiF}}$ were nearly constant, and no systematic dependences of $C_{\mathrm{SiOH}}$ and $C_{\mathrm{SiF}}$ on preparation conditions were found under the conditions tested in this study. Nevertheless, $C_{\mathrm{SiOH}}$ tended to be larger in samples with smaller $C_{\mathrm{SiF}}$. This observation is consistent with the expectation that $\mathrm{SiF}$ groups replace $\mathrm{SiOH}$ groups.

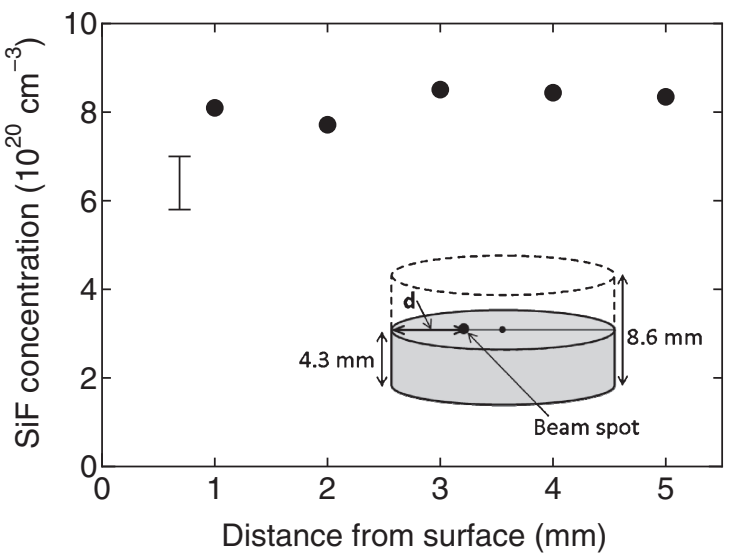

Fig. 6. Depth profile of concentration of $\mathrm{SiF}$ groups $\left(C_{\mathrm{SiF}}\right)$ measured by spatially resolved micro-Raman measurement for a sample prepared from $5.2 \mathrm{~g}$ of TEOS at $x_{1}=1, t_{\mathrm{PH}}=15 \mathrm{~min}$, and $t_{\mathrm{A}}=2$ days, followed by drying for $\sim 2$ days. $C_{\mathrm{SiF}}$ was measured at different distances from the edge, $d$, of a cross sectional surface of a cylindrical fluorine-doped silica glass (diameter: $\sim 11 \mathrm{~mm}$ ). A schematic illustration of the optical configuration is also shown. The error bar represents experimental uncertainty.

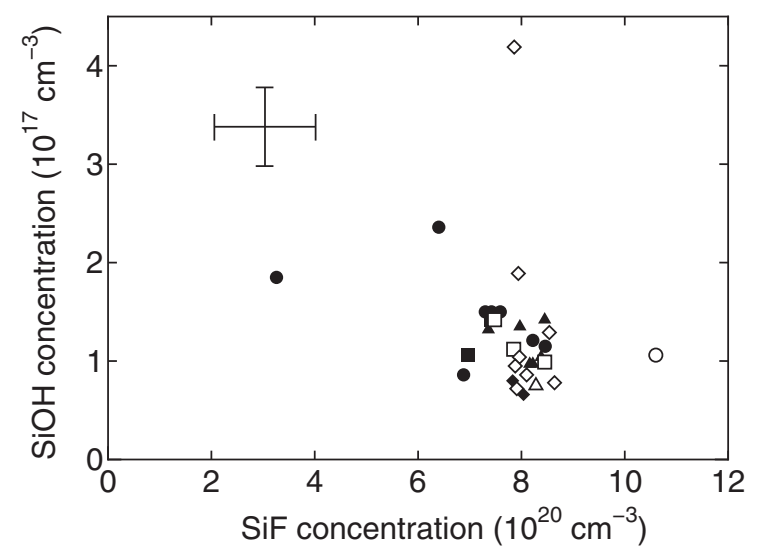

Fig. 7. Relationship between the concentrations of $\mathrm{SiOH}$ and $\mathrm{SiF}$ groups ( $C_{\mathrm{SiOH}}$ and $C_{\mathrm{SiF}}$, respectively) of samples prepared under various conditions explored in this study. Filled symbols represent systems with $x_{1}=1$ and $t_{\mathrm{PH}}=15: \square, t_{\mathrm{A}}=0 ; \diamond, t_{\mathrm{A}}=1 ; \boldsymbol{\gamma}, t_{\mathrm{A}}=2 ; \boldsymbol{\Delta}, t_{\mathrm{A}}=5$, and open symbols denote other systems with $t_{\mathrm{A}}=2: \square, x_{1}=0.5, t_{\mathrm{PH}}=15$; $\diamond, x_{1}=5, t_{\mathrm{PH}}=0 ; \bigcirc, x_{1}=2, t_{\mathrm{PH}}=15 ; \triangle, x_{1}=1, t_{\mathrm{PH}}=60$ (units: $t_{\mathrm{PH}}$, $\min ; t_{\mathrm{A}}$, days). The error bars represent experimental uncertainties.

\section{Discussion}

Fluorine-doped "dry" silica glasses were obtained by a sol-gel method, without employing vacuum sintering or sintering in flowing halogen-containing dehydrating agents. The results were surprising, because in sol-gel methods gels are commonly prepared from precursor solutions containing water, and sintering of such gels often leaves as much as $\sim 10^{19}-10^{20} \mathrm{~cm}^{-3}$ (1000 ppmw at $\left.7.8 \times 10^{19} \mathrm{~cm}^{-3}\right) \mathrm{SiOH}$ groups in the resultant silica glasses. $^{31), 34)}$

The most probable reason for the significant reduction of $\mathrm{SiOH}$ groups in this system is formation of $\mathrm{Si}-\mathrm{F}$ bonds during hydrolysis and polycondensation. ${ }^{8)-10)}$ Fluoride ions $\left(\mathrm{F}^{-}\right)$originating from $\mathrm{HF}$ act as nucleophiles. They tend to react with $\mathrm{Si}$ atoms, which are electron deficient, and form $\mathrm{Si}-\mathrm{F}$ bonds, although the $\mathrm{Si}-\mathrm{F}$ bond may be hydrolyzed by $\mathrm{H}_{2} \mathrm{O}$ remaining in the solvent phase. However, lanthanum(III)-alizarin complexone 
spectrophotometry showed that the amount of fluorine dissolved in the solvent phase was $\sim 1 \%$ of the amount incorporated initially, and confirmed that a large proportion of the fluorine was bound to the gel phase, most likely by forming SiF groups. Indeed, a Raman study confirmed the presence of $\mathrm{SiF}$ groups in gels dried at $150^{\circ} \mathrm{C} .{ }^{10)} \mathrm{A}$ possible reason for the small fluorine fraction in the solvent phase is that the $\mathrm{F}$ to $\mathrm{Si}$ ratio of the precursor solution $(\mathrm{F} / \mathrm{Si}=0.1)$ was far smaller than the ratio needed to create $\mathrm{SiF}_{6}{ }^{2-}$ ions $(\mathrm{F} / \mathrm{Si}=6)$, which are the most probable form of fluorine-containing species dissolved in the solvent phase. The incorporation of $\mathrm{SiF}$ groups decreases the concentration of $\mathrm{SiOH}$ groups in dried gels. ${ }^{10)}$ It also suppresses absorption of $\mathrm{H}_{2} \mathrm{O}$ on gel surfaces, ${ }^{11)}$ probably because the surface of silica gels becomes less hydrophilic due to the presence of hydrophobic $\mathrm{SiF}$ groups. This mechanism is consistent with the infrared absorption data shown in Fig. 3 and basically explains the low concentrations of $\mathrm{SiOH}$ groups in the fluorine-doped silica glasses prepared in this study.

From $C_{\mathrm{SiF}}$ of the silica glasses obtained in this study $\left(\sim 8 \times 10^{20} \mathrm{~cm}^{-3}\right)$ the calculated $\mathrm{F}$ to $\mathrm{Si}$ atomic ratio of these glasses was $\mathrm{F} / \mathrm{Si}=\sim 0.04$. Since the ratio expected for the dried gel was $\mathrm{F} / \mathrm{Si}=\sim 0.1$, this observation indicates that $\sim 60 \%$ of the fluorine was lost during sintering, which is caused mainly by release of $\mathrm{HF}$ and $\mathrm{SiF}_{4}{ }^{12}$ ) The release of $\mathrm{HF}$ is accompanied by removal of an $\mathrm{SiOH}$ group:

$$
\equiv \mathrm{SiF}+\mathrm{HOSi} \equiv \rightarrow \equiv \mathrm{Si}-\mathrm{O}-\mathrm{Si} \equiv+\mathrm{HF} .
$$

The release of $\mathrm{SiF}_{4}$ does not contribute to the dehydration itself. However, $\mathrm{SiF}_{4}$ is a dehydrating agent ${ }^{5)}$ and may eliminate a part of the $\mathrm{SiOH}$ groups on silica surfaces. Thus, it is most likely that the loss of fluorine during sintering plays an important role in decreasing $C_{\mathrm{SiOH}}$ to the level of $\sim 10^{17} \mathrm{~cm}^{-3}$.

\section{Conclusions}

We found that fluorine-doped chlorine-free silica glasses with low $\mathrm{SiOH}$ concentrations can be prepared by a sol-gel method without employing either chemical dehydration during sintering using halogen-containing gases, or vacuum sintering. By simply sintering HF-catalyzed gels in a helium atmosphere the concentration of $\mathrm{SiOH}$ groups is reduced to $\sim 10^{17} \mathrm{~cm}^{-3}$, which is comparable to the $\mathrm{SiOH}$ concentration of mildly-dehydrated synthetic dry silica glasses. The low $\mathrm{SiOH}$ concentration is probably due to efficient formation of $\mathrm{Si}-\mathrm{F}$ bonds in wet gels and dehydration, accompanied by loss of fluorine, during sintering. The concentration of $\mathrm{SiF}$ groups is in the order of $\sim 10^{20}$ $10^{21} \mathrm{~cm}^{-3}$ and the spatial uniformity is relatively high. This finding is useful in developing functional optical materials, including efficient silica-based phosphors and optical devices for the telecommunication spectral range.

Acknowledgments This work was partially supported by the Asahi Glass Foundation and Grant-in-Aid for Young Scientists (B) No. 22750190 from Japan Society of the Promotion of Science (JSPS).

\section{References}

1) T. Moriyama, O. Fukuda, K. Sanada, K. Inada, T. Edahiro and K. Chida, Electron. Lett., 16, 698 (1980).

2) K. Susa, I. Matsuyama, S. Satoh and T. Suganuma, Electron. Lett., 18, 499 (1982).
3) S. Sudo, M. Kawachi, T. Edahiro and T. Izawa, Electron. Lett., 14, 534 (1978).

4) S. Shibata, T. Kitagawa, F. Hanawa and M. Horiguchi, Jpn. J. Appl. Phys., 25, L902 (1986).

5) E. M. Rabinovich, D. L. Wood, D. W. Johnson, Jr., D. A. Fleming, S. M. Vincent and J. B. MacChesney, J. Non-Cryst. Solids, 82, 42 (1986).

6) K. Awazu, H. Kawazoe, K. Muta, T. Ibuki, K. Tabayashi and K. Shobatake, J. Appl. Phys., 69, 1849 (1991).

7) K. C. Cheng, Y. Xu and P. Sheu, Proc. SPIE, 5567, 983 (2004).

8) C. J. Brinker and G. W. Scherer, "Sol-Gel Science: The Physics and Chemistry of Sol-Gel Processing," Academic Press, New York (1990).

9) E. J. A. Pope and J. D. Mackenzie, J. Non-Cryst. Solids, 87, 185 (1986).

10) D. M. Krol and E. M. Rabinovich, J. Non-Cryst. Solids, 82, 143 (1986).

11) D. L. Wood and E. M. Rabinovich, J. Non-Cryst. Solids, 82, 171 (1986).

12) K. Nassau, E. M. Rabinovich, A. E. Miller and P. K. Gallagher, J. Non-Cryst. Solids, 82, 78 (1986).

13) L. L. Hench, F. G. Araujo, J. K. West and G. P. La Torre, J. Sol-Gel Sci. Technol., 2, 647 (1994).

14) F. Kirkbir, H. Murata, D. Meyers, S. R. Chaudhuri and A. Sakar, J. Non-Cryst. Solids, 178, 284 (1994).

15) F. Kirkbir, H. Murata, D. Meyers, S. R. Chaudhuri and A. Sarkar, J. Sol-Gel Sci. Technol., 6, 203 (1996).

16) S. Shibata, T. Kitagawa and M. Horiguchi, J. Non-Cryst. Solids, 100, 269 (1988).

17) A. Paleari, F. Meinardi, A. Lauria, R. Lorenzi and N. Chiodini, Appl. Phys. Lett., 91, 141913 (2007).

18) R. Lorenzi, S. Brovelli, F. Meinardi, A. Lauria, N. Chiodini and A. Paleari, J. Non-Cryst. Solids, 357, 1838 (2011).

19) R. Winter, J. B. Chan, R. Frattini and J. Jonas, J. Non-Cryst. Solids, 105, 214 (1988).

20) T. Tsukada, M. Shinmei and T. Yokokawa, J. Non-Cryst. Solids, 100, 435 (1988).

21) E. J. A. Pope and J. D. Mackenzie, J. Am. Ceram. Soc., 76, 1325 (1994).

22) E. J. A. Pope, Ph.D. dissertation, University of California, Los. Angeles (1989).

23) E. P. Barrett, L. G. Joyner and P. P. Halenda, J. Am. Chem. Soc., 73, 373 (1951).

24) S. Brunauer, P. H. Emmett and E. Teller, J. Am. Chem. Soc., 60, 309 (1938).

25) K. Kajihara, S. Kuwatani, R. Maehana and K. Kanamura, Bull. Chem. Soc. Jpn., 82, 1470 (2009).

26) K. M. Davis and M. Tomozawa, J. Non-Cryst. Solids, 201, 177 (1996).

27) G. M. Hale and M. R. Querry, Appl. Opt., 12, 555 (1973).

28) K. M. Davis, A. Agarwal, M. Tomozawa and K. Hirao, J. Non-Cryst. Solids, 203, 27 (1996).

29) T. Edahiro, M. Kawachi, S. Sudo and H. Takata, Electron. Lett., 15, 482 (1979).

30) M. Mizuguchi, L. Skuji and H. Hosono, J. Vac. Sci. Technol., $B, 17,3280$ (1999).

31) K. Kajihara, M. Hirano and H. Hosono, Chem. Commun. (Camb.), 18, 2580 (2009).

32) P. Dumas, J. Corset, W. Carvalho, Y. Levy and Y. Neuman, J. Non-Cryst. Solids, 47, 239 (1982).

33) P. Dumas, J. Corset, Y. Levy and Y. Neuman, J. Raman Spectrosc., 13, 134 (1982).

34) S. Kuwatani, R. Maehana, K. Kajihara and K. Kanamura, Chem. Lett., 39, 712 (2010). 